The author desires to express appreciation to Dr. A. M. Peter, Chief Chemist, Head of Division, for helpful suggestions and criticism received during this investigation.

Chemical Division of the $\mathbf{K} \mathbf{y}$.

AGricultural Experiment Station, LEXINGTON, KY.

\title{
SOME DATA ON THE RIPENING OF FLORIDA ORANGES.
}

By F. Alex MCDERMotr. 1

Received April 22, 1913.

The following data were obtained during the course of a study of some of the commoner enzymes occurring in the peel of the orange, with the view of ascertaining whether any change in the nature or activity of these took place at the point corresponding to the point at which the fruit became sufficiently ripe for human consumption. Previous experiments had seemed to indicate that there might be a point corresponding approximately to the development of the 7 to $\mathrm{I}$ sugar to acid ratio, where a positive reaction toward some of the ordinary oxidase reagents might be given by the peel though not given previously. This has not been found to be the case.

The fruit was all taken from one tree, at Orlando, Florida, and forwarded by express, the dates of shipment and receipt being given in the table. Tests were made on the day the fruit was received. The writer is indebted to the Orlando Citrus Growers' Association for the fruit used.

The reagents for oxidase activity used were mainly paraphenylenediamine and benzidine; tincture of guaiac, and phenolphthalin were also used, but the former was found rather less reliable than the amino-compounds, and the latter, although reacting readily to enzymes from other sources gave at best only very faint reactions with the orange peel. Aloin was also used. For the peroxidase reagents the same compounds were used, and a few drops of dilute hydrogen peroxide solution were added to the tubes. In most cases Richter's hyperol (urea with hydrogen peroxide of crystallization) was used to prepare the peroxide solution. In no case was oxidase activity detected toward any of the reagents employed, either when applied directly to the peel, or when used with aqueous extracts, either untreated or kept neutral with calcium carbonate during preparation. Strong peroxidase reactions were always obtained, both directly on the peel, and in aqueous extracts. The seeds of the ripe orange give aqueous extracts showing peroxidase reactions to benzidine and to paraphenylene diamine, but not oxidase reactions.

It has also been found that in neutral solution, the water-soluble peroxidase of the peel of the orange will resist heating for Io minutes to a temperature of $95^{\circ}$, although weakened thereby; the boiling temperature

' Florida Citrus Exchange Research Fellow. 
appears to be necessary for its complete destruction. It is, however, immediately killed by an acid medium; all attempts to secure a peroxidase reaction in orange juice after the addition of aqueous extracts of the peel, even when the juice was immediately neutralized following such addition, have failed.

Catalase activity was tested for by means of $1 \%$ hydrogen peroxide solution, used either directly on the peel, or added to aqueous extracts. When the peroxide solution was added directly to the peel in small pieces in a test tube, there was usually an evolution of oxygen in very fine bubbles from the surface of the fragments of peel, within a few seconds after the liquid was poured on. With the extracts, however, it was found that the catalase activity was very weak and transient; this was found to be due to the slight acidity of such extracts, which proved to be sufficient to destroy their catalase activity within about i 5 minutes after preparation. Subsequent extracts were therefore made by grinding the fresh peel, cut in small, thin pieces, with sand, calcium carbonate and distilled water, in a mortar, and filtering, rejecting the first few drops of filtrate, which were usually cloudy. In extracts so prepared, the catalase was much more active and more permanent. Loew ${ }^{1}$ reports catalase in oranges and lemons.

Invertase in the peel was tested for in accordance with a suggestion from Dr. C. S. Hudson, of the Bureau of Chemistry, by cutting the peel into very thin slices, which were allowed to stand in contact with a known sucrose solution, and the latter tested with the polarimeter from time to time. Invertase activity was found in the peel of the orange at all stages of ripening studied. One test for this enzyme was made on the juice, by neutralizing to phenolphthalein with o.I $N$ sodium hydroxide, and adding to a known volume of the sucrose solution; no invertase activity was detected. Martinaud ${ }^{2}$ reported that there was no invertase in the orange; he did not give the details of the tests he made on this fruit.

The invertase experiments showed that 5 grams of the fresh peel, shipment of Aug. 3, 1912, sliced thin and allowed to stand in contact with $200 \mathrm{cc}$. of a $30 \%$ sucrose solution, containing a trace of acetic acid, reduced the rotation in a $100 \mathrm{~mm}$. tube from $56.6^{\circ}$ to $45.8^{\circ}$ in 29 days. One gram of the fresh peel of the shipment of August I2th, in IOO cc. of the $30 \%$ sucrose solution, changed the rotation from $55.5^{\circ}$ to $48.5^{\circ}$ in 19 days. The solutions were protected from fermentation by means of toluene. The sucrose solution alone dropped about I degree in rotatory power in I 5 days. Five grams of the fresh peel placed in roo cc. distilled water showed a rotation of $0.8^{\circ}$ after two days; at the end of eight days this

1 U. S. Dept. Agric., Report 68, 33 (Igor).

${ }^{2}$ Compt. rend., 144, I376-8 (1907). 


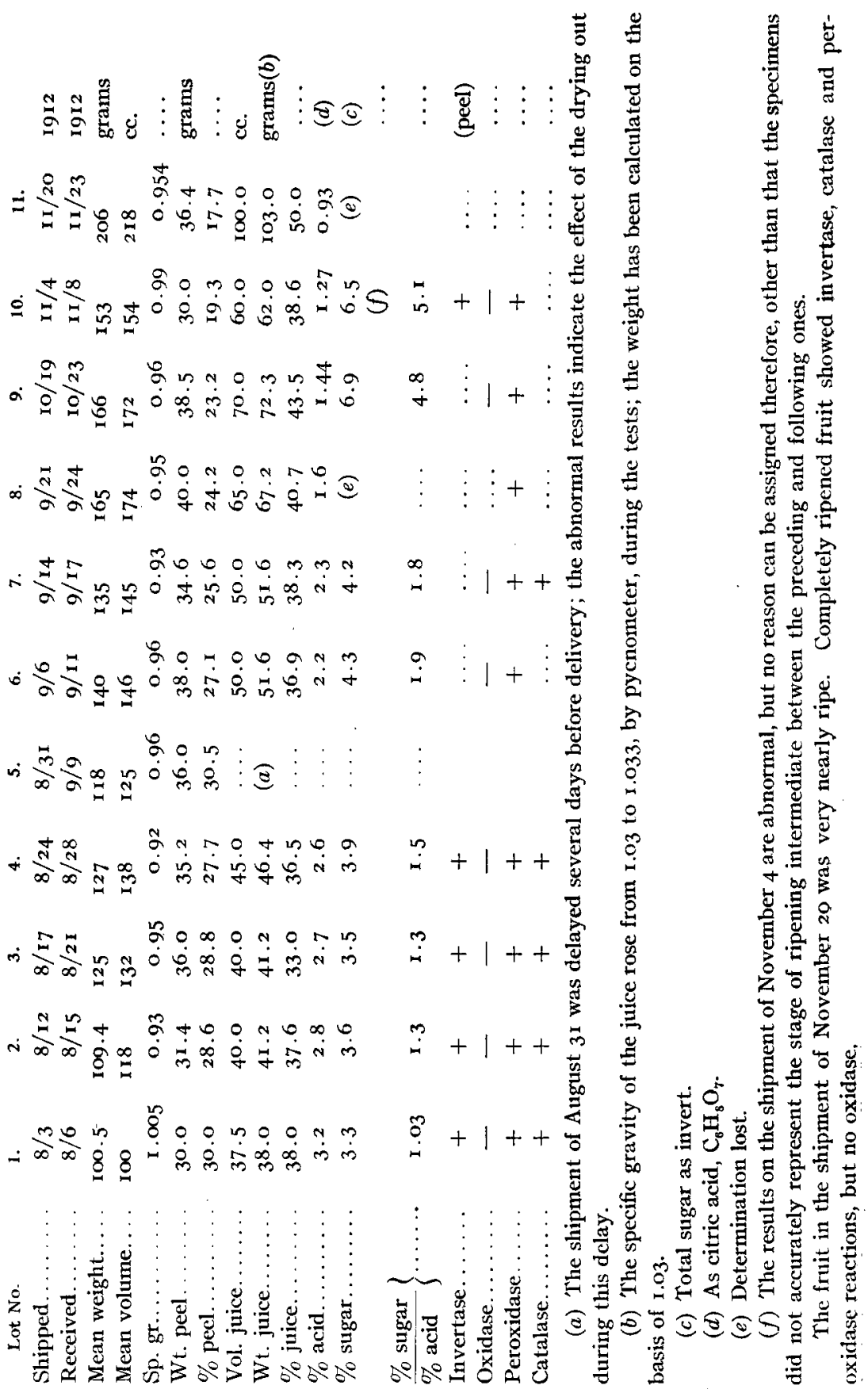


had not increased. Drying the peel in the air at room temperature did not seem to affect the invertase activity greatly. One hundred cc. of a $30 \%$ sucrose solution, showing an initial rotation of $55.5^{\circ}$ when treated with 5 grams of dried peel of the shipment of August I 2 th, showed a rotation of $20.7^{\circ}$ after 17 days.

Work of a similar nature has been done by Bigelow and Gore ${ }^{1}$ and by Scurti and DePlato; ${ }^{2}$ the results here given are quite similar to those of the former authors, and are presented mainly for the reason that these represent oranges ripening in the Florida producing region.

Summary. - The peel of the orange contains peroxidase, catalase and invertase enzymes, but no oxidase to the common reagents. During ripening, the proportion of the total weight represented by the peel decreases while that represented by the weight of the juice increases about equally in terms of percentage of the total weight. While the total amount of acid in the juice decreases only slightly, its concentration decreases materially; the sugar meanwhile increases both in concentration and in total amount. These latter results are essentially similar to those of other investigators.

University of Pittshurgh, Pittsburgh, Pa.

\section{NOTE.}

Precipitating Alkaloids by Lloyd's Reagent. ${ }^{3}$ Preliminary Note.-The brief note on John Uri Lloyd's patent ${ }^{4}$ involves reactions of intense scientific interest and wide scope, the extent of which has been perceived by no one more clearly than the discoverer himself. Reserving a more detailed statement of his labors for future publication, Professor Lloyd, at the beginning, has kindly given me the privilege of investigating the chemical and physical nature of his reagent.

This reagent is essentially hydrous aluminium silicate, derived from Fuller's earth. The reagent has the startling quality of precipitating alkaloids completely from neutral or acid solutions thereof. The alkaloid may be recovered by treatment with a base and an alkaloidal solvent. Quinine bisulfate was used exclusively in the following experiments, since Professor Lloyd himself has extended his research over a great number of alkaloids and alkaloidal salts, including those occurring in plants.

The reagent had approximately the following composition: $\mathrm{H}_{2} \mathrm{O}, 17.4 \mathrm{I} \%$; $\mathrm{SiO}_{2}, 55.30 \% ; \mathrm{Al}_{2} \mathrm{O}_{3}, 9.82 \% ; \mathrm{Fe}_{2} \mathrm{O}_{3}, \mathrm{I} 4.18 \% ; \mathrm{CaO}, \mathrm{I} .58 \% ; \mathrm{CO}_{2}, \%$ not determined. Heating the material to about $130^{\circ}$ did not destroy its.

1 This Journal, 29, 767-75 (1907).

${ }^{2}$ La Stazione Sperimentale, 41, 435-55 (1908).

${ }^{3}$ The naming of the reagent has been urged by Dr. M. I. Wilbert who was among. the first to be apprised of John Uri Lloyd's discovery.

${ }^{4}$ C. A., 7, 683 . 